\title{
INNOVACIÓN EDUCATIVA: GUÍA DE PRÁCTICAS EN UNA TELEVISIÓN LOCAL DIGITAL PARA ALUMNOS DE PERIODISMO Y COMUNICACIÓN AUDIOVISUAL
}

\section{EDUCATIONAL INNOVATION: PRACTICE GUIDE ON LOCAL TELEVISION DIGITAL STUDENTS JOURNALISM AND AUDIOVISUAL COMMUNICATION}

Beatriz Peña Acuña: Universidad San Antonio. Murcia (España) beatriz-pa@gmail.com

\section{CURRÍCULUM VITAE}

Licenciada en Filología, Diplomada en Humanidades y Periodista. Profesora de "Observación sistemática y análisis de contextos" en Magisterio Infantil, "Trabajo fin de Grado" en Turismo y "Comunicación interna" a posgrados. Profesora del Cuerpo de Tutores de la Universidad Católica San Antonio. Ha participado en diversos congresos internacionales de innovación educativa como International Conference of Education and Innovation e International Technology, Education and Development Conference con varias ponencias en inglés y ha publicado artículos concernientes a la educación en vasrias revistas científicas. Ha publicado material para docentes de Secundaria para la editorial on-line de Santillana: profes.net. Ha publicado un manual sobre "Métodos de observación aplicados a las Ciencias Sociales y la Educación" dirigido a alumnos de Magisterio. 


\section{RESUMEN}

A menudo los alumnos se lanzan a realizar su Practicum, sin conocer a qué se van a enfrentar. Este escrito pretende facilitar una guía de las posibles prácticas que tengan que realizar los alumnos de las carreras de Periodismo y Audiovisual en televisiones locales digitales.

\section{PALABRAS CLAVE}

Practicum - Televisión Local - Noticias

\section{ABSTRACT}

This paper aims to provide a guide to possible internships with students to make careers in Journalism and Audiovisual communication in a digital local television.

\section{KEY WORDS}

Practicum - Local TV - News

\section{ÍNDICE}

1. Introducción

2. Instrucciones para el alumno sobre las prácticas

3. Proceso de composición de una noticia de dos minutos incluida en un informativo 3.1. Noticias cubiertas

4. Práctica para la elaboración de un publirreportaje 
4.1. El caso del texto publicitario del publirreportaje "Restaurante Puerto Madero"

5. Práctica de observación de la grabación de un partido

6. Práctica de observación en la realización de un programa informativo

6.1. Elementos del plató

7. Práctica de observación en la revisión de la continuidad de la programación de la cadena de televisión

\section{TEXTO}

\section{Introducción}

Esta guía puede servir para aquel alumno que deba realizar prácticas en una televisión digital local de ámbito comarcal sintonizable en un canal de TDT y perteneciente a una entidad privada. El alumno puede cubrir noticias de varios municipios de una comarca. Se da el caso de que la cadena emite en verano un informativo, publicidad e incluye otros programas que incorpora desde otra empresa que incorpora mediante un contrato a través del satélite. Sin embargo, durante el invierno, la programación del canal es más amplia, pues incluye más programas temáticos, entrevistas, especiales, etc.

La peculiaridad de la televisión digital consiste en que los equipos hacen uso de técnicas de digitalización que no están sujetos a variación y ajuste, y las imágenes son estables, se regeneran sin degradación y tampoco tienen problema para el copiado y la posproducción. Además se almacena en memoria digital y es fácil de retocar y manipular. 
Previamente repasaremos algunas características de la televisión. La señal de televisión en color que leen los televisores es la suma modulada de varias señales: luminancia, crominancia, sincronismos, borrado horizontal, borrado vertical y Burst o salva de color. El sistema normativo que empleamos en España es PAL (Phase Alternate Line).

\section{Instrucciones para el alumno sobre las prácticas}

El alumno tendrá su lugar de trabajo normalmente en la redacción del periódico. Dispone de un ordenador con un navegador para usar Internet y un programa de procesador de textos donde se documenta todos los días para que las noticias tengan continuidad tanto en un periódico local digital como puede ser, por ejemplo, "Información" en el caso de Alicante, como uno nacional digital con sección Autonómica por ejemplo "El mundo". Además el alumno debe preparar la noticia tanto para televisión como para un periódico también local con otro formato y algunas modificaciones verbales, descriptivas, citas entrecomilladas, etc. En ocasiones, se le exigirá también que acompañé el texto mediante una foto digital y un pié de foto. El texto periodístico lo incluye en una carpeta del ordenador destinada a ello.

El estudiante, una vez prepara la noticia para el informativo de televisión, acude a grabar el texto sonoro a la sede de la televisión, donde lo locuta en una habitación insonorizada con un equipo de grabación y edición de sonido, y puede acudir a otra habitación habilitada para editar en dos ordenadores asimismo la noticia.

Al alumno se le ofrecen realizar otras prácticas puntuales como es la redacción de un publirreportaje publicitario, o la observación de cómo es la cobertura de un partido, 
la realización de un programa informativo o la función del que revisa la continuidad del canal de televisión.

A través de estas prácticas se pretende que el alumno conozca el alcance de una televisión local, su funcionamiento interno humano y técnico, y que además pueda poner en práctica los conocimientos adquiridos a través de sus estudios. Asimismo el becario debe observar el avance que otorgan las nuevas tecnologías y los programas informáticos a todos los procesos del formato digital en relación a los estudios que ha realizado.

Esta guía está prevista para que el estudiante realice un total de 120 horas o más de prácticas durante un mes aproximadamente.

\section{Proceso de composición de una noticia de dos minutos incluida en un informativo}

El proceso de distribución de noticias puede ser de esta forma. A primera hora en la redacción, el redactor lee las noticias en los diarios locales y lee el correo que llega de los gabinetes de prensa para que su noticia guarde continuidad. Después el redactor jefe reparte las noticias mediante el parte, una hoja en el que se informa a qué hora y qué redactores son los que acudirán a cubrir determinadas noticias, qué cámaras los acompañarán y qué fotógrafo asistirá o si ellos mismos tendrán que acudir con cámara digital.

En la primera práctica, se acude a cubrir una noticia cultural. Se trata de una rueda de prensa en el Ayuntamiento de un municipio. El redactor y el cámara forman el equipo ENG que se encargarán de cubrir la noticia. Acuden a la rueda de prensa en un coche de la cadena de televisión local a una hora convocada por la fuente. 
En la rueda de prensa el redactor tiene que tomar notas sobre la información que emiten los portavoces. En ocasiones puede recibir allí mismo una nota de prensa por parte del jefe de gabinete o el permiso para utilizar algún formato ya elaborado (por ejemplo un spot del Club de Fútbol local).

El informador va acompañado de un técnico con cámara al que pide además de una toma fija de video de las declaraciones, tomas de recursos para rellenar la noticia mientras suena la voz en off del redactor. En ocasiones, pedirá un corte a algún interlocutor y entonces, el alumno deberá formular preguntas y colocarse de espaldas a la cámara o a un lado, de modo que él no salga en pantalla y sí aparezca el entrevistado.

El técnico con cámara acude con una cámara y un trípode. Antes revisa tener el material a punto. Revisa que tiene una o dos pilas cargadas y un cassette de Mini DV de un cuarto de pulgada para grabar. Puede incluir un foco si hay poca iluminación. Éste igualmente procura que haya diversidad de planos y de ángulos para el montaje. Se utilizan normalmente dos micrófonos para recoger el sonido. Un micrófono de mano (omnidireccional) con soporte para poder ser colocado en la mesa que recoge las declaraciones y un micrófono (omnidireccional) de ambiente situado en la cámara. En ocasiones puede utilizar otro micrófono de pinza unidireccional para algún interlocutor que también se conecta a la cámara. El redactor guía al cámara dictándole cuando filma una toma fija o cuando toma imágenes de recursos debido a que el cámara se ocupa más de estar pendiente de la imagen, los planos y el sonido y no se ocupa tanto de las declaraciones de los entrevistados. 
La cámara es de marca "JVC" mini DV con una batería autónoma de grabación de más de una hora. La cámara profesional incorpora un objetivo de variable zoom y tres tubos CCD (Charge Couple Device). Asimismo posee un diafragma, y se puede realizar el balance de blancos de forma manual o automáticamente para llegar a una solución de equilibrio cromático. Para ello el cámara enfoca algún objeto que sea blanco y el resto de los colores se dispone a partir del blanco.

Además se puede añadir un filtro según se disponga de una iluminación mayor o menor del escenario. A menudo los escenarios de las ruedas de prensa no tienen buena iluminación, pues es con neón cenital, resulta dura y acentúa los rasgos de los que intervienen. En otros casos la iluminación ambiente es buena porque se trata de un edificio acristalado o con luz natural cenital. Si se equivoca el técnico de filtro, por ejemplo, pone un filtro rojo innecesario, la imagen aparecerá demasiado azul.

El técnico controla la toma y todo esto desde el visor. Asimismo regula el sonido de dos pistas de los dos micrófonos: la del sonido ambiente que tiene la cámara en la parte superior (micrófono onmidireccional), y la pista de sonido del micrófono que tiene conectado desde un cable de la cámara al micrófono de soporte (omnidireccional) con pantalla antiviento o de mesa desde el que se conecta esa cámara y otras mediante cable en una rueda de prensa.

El redactor toma fotos con una cámara digital plana porque la emisora tiene página Web y periódico también. Se realiza un volcado de texto y fotografía de la noticia en la página Web y el periódico a su vez.

De regreso a la redacción, por su parte el redactor puede revisar el correo para recibir correo del propio gabinete de prensa, si se ha tomado la molestia de enviar información, y escribe la noticia teniendo en cuenta la información del texto que 
locutará y los cortes que quiere incluir de la grabación para que no repetir demasiado el mismo contenido y que esté articulado. Por tanto, realiza un guión escrito del texto (script), junto con los cortes en los que se especifica quién es el entrevistado para que aparezcan los subtítulos debajo del corte en la posproducción final y especifica los tiempos del corte en minutos, segundo y frames (el comienzo y el final). También tiene que indicar con qué palabras empieza y acaba el corte para facilitar al editor el corte.

El cámara por su parte por medio del Avid Liquid 7 ha pasado del video digital en Mini DV que ha tomado a una imagen en formato AVID que coloca en la carpeta de Brutos porque de ahí se toman los cortes y el material de recursos. Al estar en red los ordenadores de la empresa se puede compartir en la zona del servidor con ordenadores de otro lugar del edificio, como es el caso del redactor que se separa del técnico.

Una vez tiene el guión, el redactor lo envía a tres direcciones on-line: a producción del informativo, a la locutora de informativo y a edición.

El informador después se dirige a la cabina de grabación de sonido con el guión de la noticia. Con el programa informático Protools Edit Pro locuta y graba la noticia teniendo en cuenta que el micrófono recoja la voz con suficiente volumen. Cada locución es un clip mp3 con su nombre. Todas las locuciones se graban con fecha de ese día.

El redactor una vez ha grabado la locución mediante el programa informático Protools, se dirige a editar los cortes, la locución y el relleno de imágenes con la voz de la locución en off. 
El redactor o el editor realizan todo el montaje con un programa Avid Liquid 7 dispuesto en dos pantallas de ordenador.

El editor dispone el montaje de la siguiente forma: primero se prepara el clip mp3, la pista con el material de la locución. Se borran las pistas de la locución que se ha podido repetir debido a fallos de locución. Después se prepara la pista sólo con los dos cortes de video. Tercero se unen la banda de imagen con la sonora. Cuarto se incorpora las imágenes de relleno en las que se alternan los planos medios de los cortes con los planos generales, los planos generales con panorámica unos seis segundos, con zoom, planos detalles que duran poco (unos dos segundos), con tomas con otros ángulos y saltos de eje para dar variedad. Todo ello respetando la norma de continuidad de imagen y con cortes directos. Quinto, se rellena con el sonido de relleno del micrófono de la cámara y se baja el sonido mucho para que predomine la voz en off de la locución, pero se respeta el ruido normal de un ambiente, puesto que el silencio no es creíble. Sexto, se da a la función de "Fusión" para que se convierta todo el material en AVI. Posteriormente, posproducción incorpora los subtítulos y revisa que todo el clip de la noticia haya quedado perfecto.

\subsection{Noticias cubiertas}

Los eventos que son noticiables son diversos: desde sucesos políticos de Ayuntamientos: propuestas y quejas de los concejales, recepciones, a anuncios de eventos culturales, noticias acerca de ayudas sociales, ferias empresariales, fiestas municipales, difusión de nuevas tecnologías, etc. Asimismo se cubren sucesos deportivos, por ejemplo, de sedes particulares (como el Club de Fútbol local).

\section{Práctica para la elaboración de un publirreportaje}


El comercial se pone en contacto con el cliente para publicitar su empresa en la televisión. En este caso se trata de un restaurante argentino.

El técnico con la cámara debe acudir al restaurante y realiza todo tipo de tomas. En total graba quince minutos con imágenes de día y de noche, planos detalle, cortos, medios y generales de los espacios vacíos e iluminados, o con clientes dentro del restaurante.

El cámara dispone las cámaras de la siguiente manera: una primera cámara fija que recoge tomas generales y otra segunda de planos cortos, detalles, y paneo. Si hay poca luz acude con dos focos para dar mayor iluminación y no tener que abrir tanto el diafragma, o para matizar, quitar sombras contra las paredes, o para conseguir una luz rebotada, una luz más blanda, difusa. Los focos que utiliza normalmente son los llamados "cubanitos", con luz dura.

El redactor se pone en contacto con los dueños y se asegura de recabar la información suficiente para redactar la locución para el publirreportaje. También puede documentarse por Internet en páginas especializadas en Restauración donde los clientes han dejado su opinión. El redactor elige que tipo de música va a utilizar de fondo. En este caso como es un restaurante lounge argentino utilizará el tango argentino y la música chillout. El redactor tiene que tener en cuenta que el texto sea lo suficientemente extenso para dar una información bastante detallada de cómo es el restaurante y qué ventajas de servicio ofrece el lugar para posibles clientes.

A la hora de escribir el guión de locución, el redactor tiene en cuenta las imágenes que se han tomado previamente con el objetivo de dar un cuerpo inteligente al texto. Después lo locuta y graba el texto en la sala de grabación. 
El editor puede entonces escoger y montar las imágenes según el guión de la locución y agregar la música teniendo en cuenta las partes del texto que puede estar sugerido por el redactor. Por ejemplo, en la presentación del publirreportaje se puede montar la música de tango, para el desarrollo del producto la música chillout que sirve para la descripción del negocio y para cerrar se puede poner otra música de chillout porque lo que se pretende transmitir es un restaurante en el que se come bien y se descansa con el fin de dar continuidad a la imagen de marca.

\subsection{El caso del texto publicitario del publirreportaje "Restaurante Puerto} Madero"

Previamente el redactor visiona las imágenes que ha tomado el cámara para el publirreportaje. Después se documenta de los servicios del restaurante y opiniones de fuentes como es el propio propietario o fuentes de Internet. Por fin, redacta el texto que viene a ser un guión así para el editor:

(Entrada con música de tango argentino)

En un sitio tranquilo, en la última playa, se encuentra el restaurante argentino Puerto Argentino mirando al mar con vistas a Calpe.

¿Qué le puede ofrecer Puerto Argentino?

(Cambio a una música chillout)

El punto fuerte es la buena relación calidad precio.

Ha merecido el premio al Tenedor al restaurante más reservado en 2009 en categoría argentina.

Le brinda cocina tradicional argentina con una presentación moderna.

Empiece con los entrantes 
¿Qué tal unos champiñones rellenos gratinados o unas mollejas al limón? ¿O quizás provoleta de ajo y pimientos rojos? Ummm...

Después pruebe el costillar a la cruz, el lomo alto argentino, napolitana de secreto Ibérico; las empanadas, el chorizo...

De postre, un fondue de chocolate con frutas frescas, creppe de dulce de leche o una tarta de queso artesanal.

Le propone una bodega amplia de vinos para acompañar las viandas.

Dispone de espacios cómodos para todo tipo de grupos: reuniones familiares, de negocios, de amigos... o una cena romántica en pareja.

Como es un restaurante lounge puede relajarse tomándose unas copas con música "chillout."

Los pequeños también tienen espacio de juego.

Recibirá una atención esmerada y detallista a manos de profesionales.

(Cambio de música a otra canción chillout.)

Puerto Argentino, un sitio donde puede recalar y disfrutar de los placeres del Mediterráneo.

\section{Práctica de observación de la grabación de un partido}

Para grabar el partido del equipo local en el exterior acuden tres cámaras. Se realiza la edición en el mismo lugar del partido con un RAC en el que se seleccionan los planos de las distintas cámaras, y se monta directamente junto con la voz de dos locutores que atienden el partido. 
Situadas en el mismo eje, la primera cámara se ocupa del pie del campo (toma del pasillo de vestuarios, detalles, porteros, banquillos), la segunda cámara al lado del RAC sigue la jugada general se ocupa de seguir el juego en las posiciones ataque/defensa en plano general, del medio campo en que se desarrolla la jugada. La tercera cámara fija realiza recursos de planos más cortos, faltas, etc.

Cuando el partido se emite en directo, se lleva una antena lanzadera en el RAC que por microondas envía al satélite la emisión, RETEVISIÓN lo devuelve a la antena emisora de la televisión local que a su vez lo transmite a la Comarca. Esta televisión local tiene potencia de señal según la licencia adquirida que se adscribe sólo a una Comarca, pero muy poblado al ser turística, unos doce pueblos.

Cuando se emite en diferido, el material llega con tiempo a la emisora. Sólo hay que editar el principio y el final, la emisión se realiza en AVID y se convierte para el programa de continuidad de esta televisión local: el "Videomat". El partido pasa por el proceso de programa de continuidad, es decir, se incluye dentro de una escaleta en la programación. Además se graba en varios formatos (cinta y disco duro) para tener imágenes de archivo.

\section{Práctica de observación de la realización de un programa informativo}

Pongamos el caso de un informativo se emita de lunes a viernes, en cambio el sábado y el domingo se emite el informativo sobre una selección de las noticias de esa semana. El informativo de lunes a viernes se estrena cada día a las ocho y media de la tarde y se emite en redifusión tres veces más hasta el día siguiente. 
En la grabación del informativo participan en esta cadena de televisión tres personas: el presentador, el realizador y el técnico que controla el sonido.

En el informativo hay dos presentadores: un presentador y una presentadora. Normalmente durante el invierno presenta el periodista de unos treinta años, y durante sus vacaciones le sustituye una periodista de unos cuarenta y pico años con credibilidad, conocida en la cadena por realizar un programa televisivo en invierno.

Cuando la presentadora lleva ropa o joyas para adornarse en el informativo después se da agradecimientos a esa tienda, o comercio que sirve además como publicidad para esta entidad. La presentadora suele anticipar la noticias con una pequeña presentación a la que acompaña con un gesto facial y entonación que denota cierta emoción como alegría o pena, pero todo con cierta sobriedad.

La presentadora se prepara antes de grabar el informativo. Acude a la peluquería para que la peinen. Después en la televisión dispone de una sala de maquillaje muy bien iluminada donde se maquilla bastante. A continuación dispone de la escaleta con el orden de las noticias de ese día que va a presentar y los guiones de los textos que le han facilitado los redactores con el fin de que realice una presentación previa a la noticia editada a manos de los redactores. Si se equivoca, que es frecuente, pueden repetir la grabación de la noticia.

Entre la presentadora y la sala de control donde se halla el realizador se intercomunican durante la grabación. La presentadora tiene un micrófono auricular por el que el realizador puede transmitirle alguna indicación. El técnico de sonido en la sala de control regula la intensidad del sonido general y la grabación de la presentadora. 
El contenido del informativo se estructura en tres bloques: una presentación de los titulares principales, un primer bloque que trata de un municipio grande con mucha actividad turística, publicidad fija, un segundo bloque sobre las noticias de los otros municipios, publicidad, y un tercer bloque final con los deportes y el tiempo.

El realizador dispone de un programa base informático, Avid Liquid, en el que se incluye una carpeta de "Previos" (elementos y clips) y otra de realización final facilitado por el orden del "time line" del programa informático. Éste se encarga de disponer de un documento (file) diario con este formato determinado que le da el propio programa en el que está incluida en la escaleta fija de la publicidad. El realizador dispone de la escaleta con el orden de las noticias que ha dispuesto el redactor jefe también para seguir la composición del informativo con orden y sincronizado con la presentadora.

Por un lado tiene la en la carpeta de "Previos" los clips preparados de los redactores de las noticias locutadas y ya editadas por la mañana y primeras horas de la tarde donde ya ha incluido los títulos de los entrevistados y otros infográficos, el tiempo grabado porque lo incluye a través de la pantalla croma. Después compone el informativo final mediante la incorporación de la grabación de las noticias de la presentadora que graba en falso directo por la tarde a las siete. El informativo se emite a las ocho y media.

\subsection{Elementos del plató}

El realizador dispone de tres cámaras con movimiento robotizado que sube y baja a las cámaras y realiza panorámicas. Las cámaras son dos "Fugi Non", cámaras pequeñas dollys fijas con trípode. En el informativo se utiliza una cámara con plano general y en ocasiones la otra para planos más cortos. En las entrevistas se utiliza una 
cámara para el presentador y otra para el entrevistado para dar plano/contraplano. Hay una tercera cámara, tipo grúa con un objetivo de gran angular para realizar ráfagas como plano de transición o planos generales que duran tres segundos.

La desventaja de este tipo de cámaras robotizadas es el movimiento mecánico, un poco inverosímil, más abrupto que una grabación normal.

La iluminación la prepara previamente el realizador de forma manual. Dispone de cuatro paneles de tubos fluorescentes para la iluminación general y dos focos fresner para matizar, para quitar las sombras y los contras. Ilumina por el lado derecho con un foco más fuerte y con uno menos intenso en el lado izquierdo.

Por otro lado, la sede de televisión posee un pequeño plató con acondicionamiento antirreverberante, puertas preparadas, y pavimentos adecuados, ventilación, y aire acondicionado porque hace bastante calor. La presentadora se dispone delante de una pantalla de fondo de croma verde (para que pueda aparecer por efecto visual el logo del informativo y para el tiempo) y detrás de una mesa.

\section{Práctica de observación de la revisión de la continuidad de la programación de la cadena de televisión}

Como se ha dicho anteriormente, la cadena emite programas de otra cadena por satélite como puede ser "Local media" y otros como "Euronews" o "Tatamia" (de videos musicales) que consigue tras un contrato con estas empresas. Además emite un informativo de creación propia, publirreportajes propios y otros especiales publicitarios. 
El profesional que revisa la continuidad de la programación y emisión se dispone de un programa informático "Videomat" aunque existen otros programas mejores como "Vector Box".

Este profesional cada día recibe un parte por parte del director comercial con la publicidad que deberá incluir. Tiene que tener en cuenta que se siga la programación y toma nota de que aparezcan los anuncios tal y como han sido contratados por las empresas para poder justificar que el contrato con la televisión local se ha llevado tal y como fue estipulado. Para ello realiza un registro de a qué hora se ha emitido tal publicidad. Además va permitiendo que se sintonicen los programas de satélite a su hora y que prosiga la emisión (no se quede en negro), revisa que la señal se distinga bien, etc.

Además también puede revisar el sonido del canal local de televisión privada. 